\title{
Genetic analysis of the infestation of females of the Caracu cattle breed by Horn Fly (Haematobia irritans irritans) (L.) (Diptera, Muscidae)
}

\author{
Angelina Bossi Fraga ${ }^{1}$, Maurício Mello de Alencar ${ }^{2}$, Leopoldo Andrade de Figueiredo ${ }^{3}$, \\ Alexander George Razook ${ }^{3}$ and Joslaine Noely dos Santos Gonçalves Cyrillo ${ }^{3}$ \\ ${ }^{1}$ Universidade Federal de Alagoas, Centro de Ciências Agrárias, Departamento de Zootecnia, \\ Maceió, AL, Brazil. \\ ${ }^{2}$ Embrapa Pecuária Sudeste, São Carlos, SP, Brazil. \\ ${ }^{3}$ Instituto de Zootecnia do Estado de São Paulo, Sertãozinho, SP, Brazil.
}

\begin{abstract}
The objective of this study was to evaluate environmental factors that affect infestation of Caracu cattle breed by horn fly (Haematobia irritans) and to estimate genetic parameters for level of infestation. Infestation was evaluated on females from two herds in two consecutive years. Total number of flies on animals (FC) was counted, an infestation score (FS: 1 to 5) was recorded according to the estimated number of flies on animals, and number of parasites in photographs (FF) taken when the animals were evaluated was also counted. On each animal from one to eight observations were taken. A total of 3,836, 2,751 and 3,754 records from 718 animals were obtained for FC, FF and FS, respectively. The incidence of flies was lower during winter and higher during summer, and the thicker the hair coat of the animal the greater the infestation. Heritabilities and repeatabilities were equal to 0.10 and $0.10,0.08$ and 0.12 , and 0.06 and 0.08 , for FC, FF and FS, respectively. Findings indicate that selection for FC will result in low genetic progress and that animals should be evaluated more than once for selection purposes.
\end{abstract}

Key words: genetic correlation, heritability, horn fly counts, repeatability.

Received: March 19, 2004; Accepted: September 29, 2004.

\section{Introduction}

Incidence of parasite infestations in the tropics has been the cause of losses in productivity. Today, horn fly (Haematobia irritans, Linnaeus) is considered one of the most important and widely spread parasites in several countries, Brazil included. It was introduced in Brazil about two decades ago and it is already established in almost every state of the country and in most of the South-American countries (Bianchin et al., 1992). In addition to its bloodfeeding activity, the irritating action and the sores resulting from its continuous bites result in a condition of considerable stress to animals. The main economical losses caused by this fly can be attributed to decrease in weight gain, milk production, and feed efficiency.

The main method used to control this parasite has been the application of chemical products, which increase costs and may leave residues in beef and milk. According to Brown et al. (1992), continuous applications of insecticides

Send correspondence to Angelina Bossi Fraga. Universidade Federal de Alagoas, Centro de Ciências Agrárias, Departamento de Zootecnia, Campus Delza Gitaí, BR 104 Norte, km 85, 57.100-000 Maceió, AL, Brazil. E-mail: agelina @ ceca.ufal.br. for several years will result in resistance of the parasites to that product and make natural selection of the hosts to the parasites not viable. Barros (2003) indicates that today, in Brazil, resistance of horn fly to pyrethroid insecticides occurs all over the country. Lasley (1987) stated that resistance of cattle to parasites is apparently determined by many pairs of genes, involving additive gene action and causing, therefore, variation among individuals in a population. Considerable differences in number of infesting flies among individuals of the same breed and of different breeds were observed by Steelman et al. (1991) and Brown et al. (1992).

Although the physiological mechanisms involved in development of resistance to horn fly are not yet clear, it is believed that resistance is a poligenic trait, most of the genes with additive action and little or none dominance, overdominance and epistatic effects (Brown et al., 1992). Genetic variability in resistance to Haematobia irritans indicates that selection of resistant hosts together with other controlling practices may result in a promising method of control.

Besides the genetic effect, several environmental factors can affect horn fly population dynamics in the herds. 
Among these factors, year and season, age, sex and hair color of the animal can be listed. Knowing these factors is important when estimating an animal's genetic potential for parasite resistance, and also as a guide for parasite control.

The objective of this work was to study some environmental factors affecting infestation level of Caracu cattle by horn fly (Haematobia irritans) and to estimate genetic and phenotypic parameters for the trait, for the purpose of establishing selection criteria to increase cattle resistance to this parasite.

\section{Materials and Methods}

This study was undertaken with data on Caracu females from two herds owned by the Sertãozinho Experimental Station (Instituto de Zootecnia), located North of the State of São Paulo, and by Caracu do Ipê Farm, at Paranaíba, State of Mato Grosso do Sul, Brazil.

Naturally infested animals were submitted to periodical evaluations of level of infestation by horn fly (Haematobia irritans), from July, 1998 to July, 2000, at least 90 days after a controlling chemical product was applied. In both years, the product used to control the parasite, when infestation was high, was a pyrethroid insecticide (cypermethrin).

The most widely used method to evaluate resistance of cattle to Haematobia irritans has been counting the infesting flies (Steelman et al., 1991; Brown et al., 1992; Baron and Lysyk, 1995). In this study, three different methods were used. The first (FC) consisted of counting the number of flies present on animal's body surface (dorsal and left ventral regions), while it was held in a chute. These countings were done by the same person throughout the experiment, with a manual counter. The second method (FF) consisted of counting the number of flies in a photograph of the dorsal region of the animal's body, where flies concentrate, using a $0.15 \mathrm{~m}^{2}$ trapezoidal wire structure to delimit the area. Photographs were taken with a manual camera, while the animals were in the working chute, using professional film (VC - 400 ASA), with day light only, at a distance of one meter from the animal's back, at a $90^{\circ}$ angle to the animal's body surface. The third method (FS) consisted of recording an infestation score according to the estimated number of flies on the animal: score 1 for $\leq 100$ flies per animal; score 2 for $>100$ and $\leq 200$ flies per animal; score 3 for $>200$ and $\leq 300$ flies per animal; score 4 for $>300$ and $\leq 400$ flies per animal; and score 5 for $>400$ flies per animal.

Data from the Animal Science Experimental Station at Sertãozinho contained 1,520 records on 245 animals, the offspring of 39 bulls and 166 cows. Data from the Caracu do Ipê Farm contained 2,796 records on 792 animals, the offspring of 58 bulls and 292 cows. Animals were evaluated, on average, six times, with a minimum of one and a maximum of eight records. A total of 3,836, 2,751 and 3,754 records were obtained for FC, FF and FS, respectively. The working file consisted of 4,316 observations.

Animals were classified according to hair coat color into one of three classes: 1- bay, 2- orange, and 3-red. Hair coat thickness was measured with a modified rule, introduced softly under the hair coat surface up to the insertion base of the hair, on the skin surface of the shoulder of the animal. Hair coat thickness, determined in $0.5 \mathrm{~cm}$ classes, varied from 0.5 to $6.5 \mathrm{~cm}$; however, classes $\geq 3.5$ were grouped in one class.

Four seasons of the year were considered: spring, for records taken in September, October and November; summer, for records taken in February and March; fall, for records taken in April and May; and winter, for records taken in July. In addition, year of observation was also codified: year 1, for records taken from September, 1998 to July, 1999; and year 2, for records taken from September, 1999 to July, 2000.

The observed data were transformed to $\log _{10}(n+1)$ for countings, and $(\mathrm{x})^{1 / 2}$ for score, where " $\mathrm{n}$ " is the number of flies counted on the animal and in the photograph and " $x$ " is the score of infestation of flies (1 to 5).

After transformations, traits were analyzed by the least squares method, using the GLM procedure (SAS, 1996), to evaluate some sources of variation affecting these traits. The statistical model included fixed effects of herd $(\mathrm{H}=1$ and 2$)$, color of the animal $(\mathrm{C}=1,2$ and 3$), \mathrm{Hx} \mathrm{C}$, animal within $\mathrm{H} x \mathrm{C}$ (error a, to test effects $\mathrm{H}, \mathrm{C}$ and $\mathrm{H} x \mathrm{C}$ ), year $(Y=1$ and 2$)$ and season $(S=1,2,3,4$; spring, summer, fall and winter, respectively) of recording, hair coat thickness (1 to 3.5) and age of the animal as a covariate (linear and quadratic effects), plus random error.

Variance and covariance components estimates, to obtain genetic parameters (heritability and genetic correlations), repeatability and phenotypic correlations, were obtained by the derivative free restricted maximum likelihood method (DFREML), using the MTDFREML program (Boldman et al., 1993). The statistical model included, besides the additive direct and permanent environmental random effects, fixed effects of contemporary group (GC; herd-year-season), hair coat thickness and age of the animal as a covariate (linear and quadratic effects). The statistical model, in matrix notation, was:

$$
\mathrm{y}=\mathrm{Xb}+\mathrm{Za}+\mathrm{Pp}+\mathrm{e} ;
$$

where: $\mathrm{y}=$ vector of observations; $\mathrm{X}=$ incidence matrix for fixed effects; $b=$ vector of fixed effects (GC, hair coat thickness and age); $\mathrm{Z}=$ incidence matrix for additive direct effect of the animal; $\mathrm{a}=$ vector of additive direct effects; $\mathrm{P}=$ incidence matrix for permanent environmental and non-additive genetic effects; $p=$ vector of permanent environmental effect due to the animal (non-additive genetic effects due to the animal); and $\mathrm{e}=$ vector of residual random effects, associated to observations. 
Assumptions adopted for the model were: $\mathrm{E}(\mathrm{y})=\mathrm{Xb}$; $\mathrm{E}(\mathrm{a})=0 ; \mathrm{E}(\mathrm{p})=0 ; \mathrm{E}(\mathrm{e})=0 ; \operatorname{var}(\mathrm{a})=\mathrm{A} \sigma_{\mathrm{a}}^{2} ; \operatorname{var}(\mathrm{p})=\mathrm{I}_{\mathrm{K}} \sigma_{\mathrm{p}}^{2}$; $\operatorname{var}(\mathrm{e})=\mathrm{I}_{\mathrm{N}} \sigma_{\mathrm{e}}^{2}$, where $\mathrm{A}$ is the relationship matrix, $\sigma_{\mathrm{a}}^{2}$ is the additive direct variance component, $\sigma_{p}^{2}$ is the permanent environmental variance component, $\sigma_{\mathrm{e}}^{2}$ is the residual variance component, $\mathrm{N}$ is the number of observations, $\mathrm{I}$ is a identity matrix of order $\mathrm{N}$, and $\mathrm{k}$ is the number of animals.

For each trait, a one-trait analysis using the above model was undertaken. Two-trait analyses were also undertaken to estimate correlations between FC and FF and between FC and FS.

\section{Results and Discussion}

Means, minimum and maximum values, standard deviations and coefficient of variation of the traits studied are presented in Table 1.

Due to differences among regions and seasons of evaluation, and sex, breed and age effects, and to possible control strategy differences, it can be seen that the number of infesting flies in this study is higher than those observed by Bianchin et al. (1992), in Nellore breed in Brazil, and Brown et al. (1992), in Chianina breed in the United States. However, the mean number of infesting flies observed in this study is lower than values reported by Brown et al. (1992) in animals of Angus, Charolais, Hereford, Polled Hereford and Red Polled breeds in the United States.

The mean number of flies in photographs (FF) was lower than the mean number counted on the animals (FC), as expected, since the photograph represents just a small part of the dorsal region of the animal, while FC represents the whole body.

The summary of the analyses of variance of the traits studied is presented in Table 2. Herd $\mathrm{x}$ color interaction $(p<0.01)$ and color effect $(p<0.05)$ were significant only for FF. Interaction was significant because there was no difference between colors 2 and 3 in the Animal Science Experimental Station at Sertãozinho, and in Caracu do Ipê Farm there was no difference between colors 1 and 2. In the

Table 1 - Descriptive statistics of number of flies counted on animals (FC), number of flies in photographs (FF), and of infestation score (FS).

\begin{tabular}{lccc}
\hline Trait & $\mathrm{FC}^{1}$ & $\mathrm{FF}^{1}$ & $\mathrm{FS}^{2}$ \\
\hline Mean $^{3}$ & 1.8087 & 1.3087 & 1.2014 \\
& $(106.4)$ & $(39.1)$ & $(1.54)$ \\
Minimum $^{3}$ & 0.0000 & 0.0000 & 1.0000 \\
& $(0)$ & $(0)$ & $(1)$ \\
Maximum $^{3}$ & 3.2600 & 3.1800 & 2.2361 \\
& $(1809)$ & $(1528)$ & $(5)$ \\
Standard $_{\text {deviation }}^{3}$ & 0.4774 & 0.5096 & 0.3145 \\
Coefficient of & $(128.4)$ & $(65.5)$ & $(0.92)$ \\
variation $(\%)$ & 26.39 & 38.94 & 26.18 \\
\hline
\end{tabular}

${ }^{1} \log _{10}(\mathrm{n}+1) ;{ }^{2}(\mathrm{x}){ }^{1 / 2} ;{ }^{3}$ Numbers within parentheses are untransformed values.
Table 2 - Summary of the analyses of variance of number of flies counted on animals (FC), number of flies in photographs (FF), and of infestation score (FS).

\begin{tabular}{lrrcc}
\hline \multirow{2}{*}{$\begin{array}{l}\text { Source of } \\
\text { variation }\end{array}$} & & \multicolumn{3}{c}{ Mean squares } \\
\cline { 3 - 5 } & DF & FC & FF & FS \\
\hline Herd (H) & 1 & $2.4454^{* *}$ & $3.3891^{* *}$ & $1.2521^{* *}$ \\
Color (C) & 2 & 0.2920 & $0.8208^{*}$ & 0.0919 \\
H x C & 2 & 0.2641 & $1.2696^{* *}$ & 0.0953 \\
Animal: H x C & $714^{1}$ & 0.2190 & 0.2733 & 0.0913 \\
Year & 1 & 0.0887 & $0.8413^{*}$ & 0.0077 \\
Season & 3 & $7.2371^{* *}$ & $11.9398^{* *}$ & $5.4451^{* *}$ \\
Hair coat & 5 & $0.4059^{*}$ & 0.3323 & $0.5085^{* *}$ \\
thickness & 1 & 0.0549 & $1.4144^{* *}$ & 0.0039 \\
Age linear & 1 & $2.5851^{* *}$ & $0.8289^{*}$ & 0.0001 \\
Quadratic & 3105 & 0.1619 & & \\
Error & 2075 & & 0.1928 & \\
& 3030 & & & \\
\hline $\mathrm{R}^{2}(\%)$ & & 42 & 44 & 40 \\
\hline
\end{tabular}

${ }^{1} 713$ for FS and 659 for FF.

${ }^{*} \mathrm{p}<0.05 ;{ }^{* *} \mathrm{p}<0.01$.

first herd, number of flies (FC) was greater for color 1 (bay) animals than for animals of color 2 (orange) or 3 (red). In the other herd, color 1 and 2 animals presented higher number of flies than color 3 ones (Figure 1).

Effect of herd was significant $(\mathrm{p}<0.01$; Table 2$)$ for all traits studied. Number of flies was higher in the Animal Science Experimental Station at Sertãozinho (1.99 \pm 0.06 vs. $1.61 \pm 0.05$ for $\mathrm{FC}, 1.76 \pm 0.10$ vs. $0.88 \pm 0.11$ for $\mathrm{FF}$, and $1.36 \pm 0.04$ vs. $1.08 \pm 0.03$ for FS) than in the Caracu do Ipê Farm. Despite the herd x color interaction for FF, animals from the Animal Science Experimental Station at Sertãozinho showed higher number of flies in photographs than animals from the Caracu do Ipê Farm, regardless of color of the animals (Figure 1).

Effect of year of observation was significant only for FF ( $p<0.05$; Table 2). In this case, the number of flies was greater for year 2 than for year $1(1.64 \pm 0.15 v s$. $1.00 \pm 0.16)$.

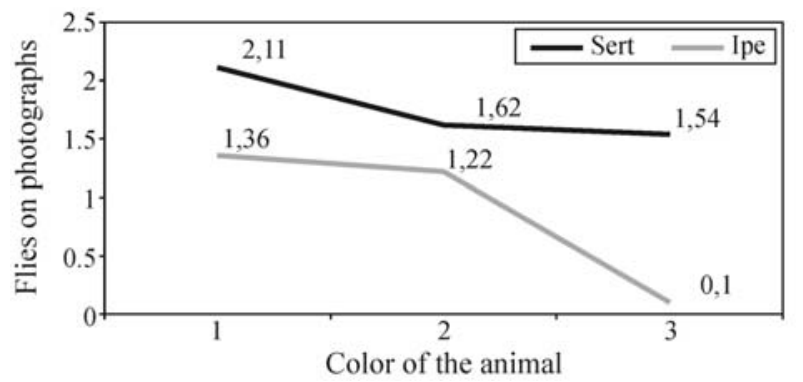

Figure 1 - Mean number of flies according to hair color ( $1=$ bay, $2=$ orange, and $3=$ red) and herd. 
Season of the year affected significantly $(\mathrm{p}<0.01)$ all traits studied (Table 2). Estimated means are presented in Table 3. Number of flies counted on the body of the animals (FC) showed a peak in spring and in summer, and fell in winter. Similarly, scores (FS) attributed in spring and in fall were similar in magnitude to each other and were within the range of those attributed in summer, which were the highest ones, and those attributed in winter, which were the lowest ones. Lima et al. (2003) observed, in Nellore cattle in Araçatuba, State of São Paulo, higher infestations of horn fly during the spring and fall. These results suggest that the infesting population of horn flies grows during the seasons favorable to its free life phase, that is, when temperature, relative humidity of the air and precipitation parameters are adequate to its development, as reported by Winslow (1992).

This assumption, however, is not valid when number of flies is evaluated by FF. In this case, infestation was lower in spring, higher in fall, and medium in summer and in winter (Table 3 ). This fact suggests that the photograph method, at least the way it was conducted in this study, did not present results compatible with the other methods used. These discrepancies can be attributed to several hypotheses. During the experiment, there was no uniformity of the moment the pictures were taken, as far as light intensity (sun, rain or cloudy weather) is concerned, an important condition for the quality of the pictures. In addition, in regard to the region of the animal's body preferred by the insect, it was observed that flies show a distinct behavior in each situation. In a rainy weather, for example, they prefer the lower regions, like legs and ventral region, away from photographs target. This behavior was also observed by Lima et al. (2002a). However, it is believed that a group of factors contributed to these results, which do not turn the method unviable, but indicate the need for improvement.

According to analyses of variance, hair coat thickness affected significantly FC ( $p<0.05)$ and FS $(\mathrm{p}<0.01)$ (Table 2). In general, there was a tendency for increasing FC and FS with increasing hair coat thickness (Table 4), suggesting that animals with short hair coat thickness are those best adapted and, consequently, the least infested ones.

Table 3 - Least square means ( \pm standard error) of number of flies counted on animals (FC), number of flies in photographs (FF), and of infestation score (FS), according to season.

\begin{tabular}{|c|c|c|c|}
\hline \multirow[b]{2}{*}{ Season } & \multicolumn{3}{|c|}{ Means ( \pm standard error) } \\
\hline & $\mathrm{FC}^{1}$ & $\mathrm{FF}^{1}$ & $\mathrm{FS}^{1}$ \\
\hline Spring & $1.90 \pm 0.04$ & $1.06 \pm 0.13$ & $1.25 \pm 0.03$ \\
\hline Summer & $1.92 \pm 0.02$ & $1.30 \pm 0.04$ & $1.32 \pm 0.01$ \\
\hline Fall & $1.82 \pm 0.02$ & $1.56 \pm 0.04$ & $1.26 \pm 0.02$ \\
\hline Winter & $1.56 \pm 0.04$ & $1.36 \pm 0.10$ & $1.06 \pm 0.03$ \\
\hline
\end{tabular}

${ }^{1}$ Transformed traits.
Age of animals varied from 207 days to 6,038 days, with mean of $1,866.62$ days and standard variation of 1,179.15 days. The quadratic effect of age of the animal was significant for FC $(p<0.01)$ and FF $(p<0.05)$, and the linear effect was significant $(\mathrm{p}<0.01)$ for FF. Regression equations were $\mathrm{y}=1.4364-0.000179$ (Age) + $0.000000074(\text { Age })^{2}$ and $\mathrm{y}=3.7612-0.002198$ (Age) + $0.000000060(\mathrm{Age})^{2}$ for FC and FF, respectively. Number of flies (FC) was minimum for 1,195 day (3.27 years) old animals. Number of flies on photographs tended to fall to zero on animals between four and five years of age.

Variance components, heritability and repeatability estimates, obtained by the one-trait analyses, are presented in Table 5. All three traits showed low and similar heritability estimates $(0.10,0.08$ and 0.06 for FC, FF and FS, respectively). Brown et al. (1992) obtained values of 0.78 and 0.59 for animals of Angus, Charolais, Chianina, Hereford, Polled Hereford and Red Poll breeds, using the least squares method and paternal half-sib intraclass correlation and within sire daughter-dam regression, respectively.

These results show that it is difficult to increase animals' resistance to horn fly by mass selection, and that, in terms of heritability, the methods of photographs (FF) and scores (FS) were not superior to counting of flies on the animal (FC). These traits present, however, high phenotypic

Table 4 - Least square means ( \pm standard error) of number of flies counted on animals (FC), number of flies in photographs (FF), and of infestation score (FS), according to hair coat thickness.

\begin{tabular}{lccc}
\hline & \multicolumn{3}{c}{ Mean $( \pm$ standard error $)$} \\
\cline { 2 - 4 } Hair thickness & $\mathrm{FC}^{1}$ & $\mathrm{FF}^{1}$ & $\mathrm{FS}^{1}$ \\
\hline $1.0(\leq 1.2 \mathrm{~cm})$ & $1.77 \pm 0.02$ & $1.28 \pm 0.03$ & $1.15 \pm 0.01$ \\
$1.5(1.2 \leq 1.7 \mathrm{~cm})$ & $1.75 \pm 0.02$ & $1.27 \pm 0.02$ & $1.17 \pm 0.01$ \\
$2.0(1.7 \leq 2.2 \mathrm{~cm})$ & $1.81 \pm 0.02$ & $1.27 \pm 0.02$ & $1.22 \pm 0.01$ \\
$2.5(2.2 \leq 2.7 \mathrm{~cm})$ & $1.83 \pm 0.03$ & $1.33 \pm 0.03$ & $1.25 \pm 0.02$ \\
$3.0(2.7 \leq 3.2 \mathrm{~cm})$ & $1.80 \pm 0.03$ & $1.34 \pm 0.04$ & $1.26 \pm 0.02$ \\
$3.5(>3.2 \mathrm{~cm})$ & $1.83 \pm 0.05$ & $1.42 \pm 0.07$ & $1.28 \pm 0.04$ \\
\hline
\end{tabular}

${ }^{1}$ Transformed traits.

Table 5 - Variance components, heritability, and repeatability of number of flies counted on animals (FC), number of flies in photographs (FF), and infestation score (FS), obtained by the one-trait analyses.

\begin{tabular}{lccccccc}
\hline Trait & $\sigma_{\mathrm{a}}{ }^{2}$ & $\sigma_{\mathrm{e}}{ }^{2}$ & $\sigma_{\mathrm{p}}{ }^{2}$ & $\sigma_{\mathrm{T}}{ }^{2}$ & $\mathrm{~h}^{2}$ & $\mathrm{c}^{2}$ & $\mathrm{t}$ \\
\hline FC & 0.01499 & 0.13885 & 0.00000 & 0.15383 & 0.10 & 0.00 & 0.10 \\
FF & 0.01667 & 0.17505 & 0.00614 & 0.19786 & 0.08 & 0.03 & 0.12 \\
FS & 0.00400 & 0.06526 & 0.00199 & 0.07125 & 0.06 & 0.03 & 0.08 \\
\hline
\end{tabular}

${ }^{1} \sigma_{\mathrm{a}}{ }^{2}, \sigma_{\mathrm{e}}{ }^{2}, \sigma_{\mathrm{p}}{ }^{2}, \sigma_{\mathrm{T}}{ }^{2}, \mathrm{~h}^{2}, \mathrm{c}^{2}$, and $\mathrm{t}=$ additive direct, residual, permanent environmental (non-additive genetic, due to the animal) and total phenotypic variance components, heritability, permanent environmental to total phenotypic components ratio, and repeatability. 
variations, so that it is possible to obtain higher selection differentials and some response to selection.

Variance component of permanent environmental (non-additive genetic effect) effect was close to zero for all traits studied (Table 5). Repeatability values obtained for these traits (0.08 to 0.12) are lower than the value of 0.47 obtained by Brown et al. (1992) using the least squares method.

Heritability, repeatability, and genetic, permanent environmental (non-additive genetic), residual and phenotypic correlations for traits studied, obtained by the two-trait analyses, are presented in Table 6. Estimates of heritability and repeatability are the same and similar to those obtained by the one-trait analyses.

Estimates of genetic correlations of FC with $\mathrm{FF}$ and FC with FS are high (Table 6), suggesting that most of the genes with additive action that affect one trait also affect the other, and that selection for one of the traits should result in correlated response in the other. These high correlations can be seen by the relationship between the estimated breeding values of the animals for these traits, shown in Figures 2 and 3, respectively.

Considering heritability and genetic correlation estimates obtained in this study and the same selection intensity for the two traits, selection for $\mathrm{FF}$ is $90 \%$ as effective as selection for FC to promote changes in FC. On the other hand, selection for FS will be only $63 \%$ as effective as the direct selection for FC. So, it seems that the photograph method can replace direct counting of flies on the animal, due to its quickness and precision in fieldwork. However, the method needs to be improved. In a study comparing estimative counting and counting using a film camera method, Lima et al. (2002b) reported superiority of the camera method of counting horn fly due to its precision, ease and low cost. The authors indicated this method in cases where more precise results are needed.

Permanent environmental correlations, or nonadditive genetic correlation due to the animal, were close or equal to one for all estimates obtained (Table 6). This indicates that non-additive genetic factors of the animal, that is, those related to non-temporary environment and to allele and gene combinations that affect one trait also affect the

Table 6 - Heritability, repeatability and genetic and phenotypic correlations of number of flies counted on animals (FC), number of flies in photographs (FF), and infestation score (FS), obtained by the two-trait analyses.

\begin{tabular}{|c|c|c|c|c|c|c|c|c|c|}
\hline \multicolumn{2}{|c|}{ Trait } & \multicolumn{8}{|c|}{ Estimates $^{1}$} \\
\hline 1 & 2 & $\mathrm{~h}_{1}^{2}$ & $\mathrm{~h}_{2}^{2}$ & $t_{1}$ & $t_{2}$ & $\rho_{\mathrm{a} 12}$ & $\rho_{\mathrm{p} 12}$ & $\rho_{\mathrm{e} 12}$ & $\rho_{\mathrm{T} 12}$ \\
\hline $\mathrm{FC}$ & $\mathrm{FF}$ & 0.10 & 0.09 & 0.10 & 0.10 & 0.95 & 1.00 & 0.44 & 0.48 \\
\hline $\mathrm{FC}$ & FS & 0.10 & 0.07 & 0.10 & 0.08 & 0.75 & 0.99 & 0.62 & 0.63 \\
\hline
\end{tabular}

${ }^{1} \mathrm{~h}_{\mathrm{i}}{ }^{2}, \mathrm{t}_{\mathrm{i}}, \rho_{\mathrm{a} 12}, \rho_{\mathrm{p} 12}, \rho_{\mathrm{e} 12}$ and $\rho_{\mathrm{T} 12}=$ heritability, repeatability and genetic, permanent environmental, residual and phenotypic correlations between traits 1 and 2, respectively.

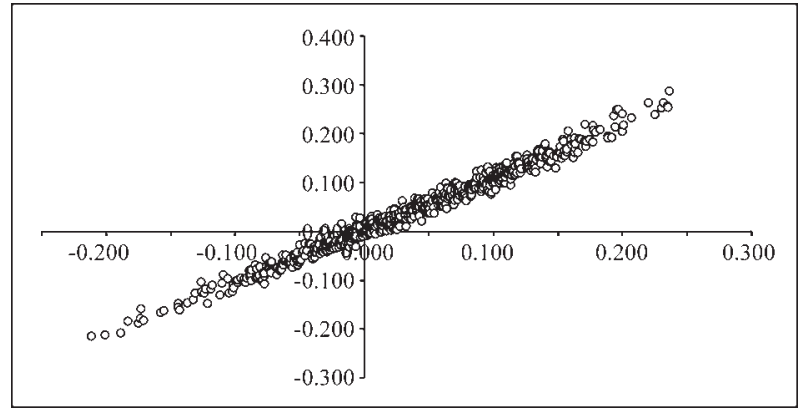

Figure 2 - Relationship between the animals' estimated breeding values for number of flies counted (FC; $\mathrm{x}$ axis) and number of flies in photographs (FF; y axis).

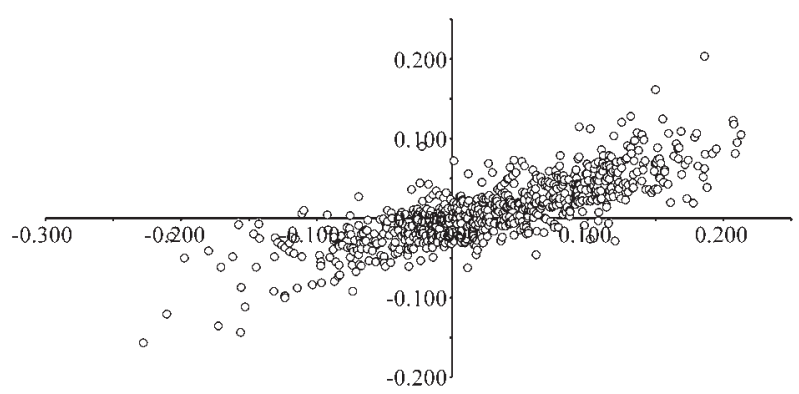

Figure 3 - Relationship between the animals' estimated breeding values for number of flies counted (FC; $x$ axis) and infestation score (FS; $y$ axis).

other. Environmental (non-permanent or temporary) correlations were of medium magnitude (Table 6).

Relationships among phenotypic, additive genetic, permanent environmental (non-additive genetic due to the animal) and environmental (residual or non-permanent or temporary environmental) correlations can be expressed by the following equation:

$$
\rho_{\mathrm{P} 12}=h_{1} \cdot \rho_{\mathrm{a} 12} \cdot \mathrm{h}_{2}+\mathrm{c}_{1} \cdot \rho_{\mathrm{pe} 12} \cdot \mathrm{c}_{2}+\mathrm{e}_{1} \cdot \rho_{\mathrm{e} 12} \cdot \mathrm{e}_{2}
$$

where $h_{i}=$ square root of the heritability of trait $i$; $c_{i}=$ square root of the permanent environmental to total phenotypic variance component ratio; $\mathrm{e}_{\mathrm{i}}=$ square root of the residual or non-permanent or temporary environmental to total phenotypic variance component ratio; and $\rho_{\mathrm{P} 12}, \rho_{\mathrm{a} 12}$, $\rho_{\mathrm{pe} 12}$ e $\rho_{\mathrm{e} 12}=$ phenotypic, additive genetic, permanent environmental and residual correlations, respectively. Regarding this relationship among correlations, the contribution of the additive genetic, the non-additive genetic due to the animal (non-additive genetic and permanent environmental) and environmental (residual or temporary) components to phenotypic correlation between FC and FF were $18.27 \%$, $0.60 \%$, and $81.13 \%$, respectively. For correlation between FC and FS, they were, in the same order, 9.95\%, 0.19\%, and $89.86 \%$, respectively. Then, despite the fact that permanent environmental correlations are close to one (Table 6), permanent environmental components contributed just a little to phenotypic correlations of the traits. Environmen- 
tal components contributed with most of phenotypic correlation of the traits. For correlation between FC and FF, additive genetic component contribution was important, despite the fact that it was not the highest.

\section{Conclusions}

Incidence of horn flies in Caracu cattle in the regions studied is lower in winter and higher in spring, summer and fall.

Hair coat thickness is an important factor determining infestation of Caracu cattle by horn flies, and infestation is greater the thicker the hair coat is.

There is low additive genetic variation for level of infestation of cattle by horn flies, justifying its inclusion in a selection program only if selection intensity is high.

Counting of horn flies in cattle with photographs can replace direct counting of flies on animal's body.

\section{Acknowledgements}

The authors would like to thank CAPES (Coordenadoria de Aperfeiçoamento de Pessoal de Nível Superior) for a graduate scholarship given to A.B.F., CNPq (Conselho Nacional de Desenvolvimento Científico e Tecnológico) for a graduate scholarship given to J.N.S.G.C. and fellowships given to M.M.A. and A.G.R., and Mr. Diomário Faustino Dias de Barros and Estação Experimental de Zootecnia de Sertãozinho for providing the Caracu herds used in this study.

\section{References}

Baron RW and Lysyk TJ (1995) Antibody responses in cattle infested with Haemabobia irritans irritans (Diptera: Muscidae). Journal of Medical Entomology 32:630-635.

Barros ATM (2003) Horn fly resistance to insecticides in South America: History and current status. In: $5^{\text {th }}$ International
Seminar of Animal Parasitology, Yucatan, México, pp 173-176.

Bianchin I, Honer MR, Koller WW, Gomes A and Schenk JAP (1992) Desenvolvimento de um programa integrado de controle dos nematódeos e a mosca-dos-chifres na região dos cerrados. Fase 5. Efeito da mosca-dos-chifres sobre o ganho de peso de vacas e bezerros Nelore. Campo Grande, EMBRAPA-CNPGC, Comunicado Técnico 46, 8 pp.

Boldman KC, Kriese LA, Van Vleck LD and Kachman SD (1993) A Manual for Use of MTDFREML. A Set of Programs to Obtain Estimates of Variance and Covariance. [DRAFT] Clay Center: U. S. Department of Agriculture, Agricultural Research Service, 120 pp.

Brown Jr AH, Steelman CD, Johnson ZB, Rosenkrans Jr CF and Brasuell TM (1992) Estimates of repeatability and heritability of horn fly resistance in beef cattle. J Anim Sci 70:1375-1381.

Lasley JF (1987) Genetics of livestock improvement. 4th edition. Prentice-Hall, Inc., Englewood Cliffs, NJ, 477 pp.

Lima LGF, Perri SHV and Prado AP (2003) Variation in population density of horn flies (Haematobia irritans) (L.) (Diptera: Muscidae) in Nellore cattle (Bos indicus). Vet Parasitol 117:309-314.

Lima LGF, Prado AP and Perri SHV (2002a) Localização preferencial e índices diferenciados de infestação da mosca-doschifres (Haematobia irritans) em bovinos da raça Nelore. Pesq Vet Bras 22:25-32.

Lima LGF, Prado AP and Perri SHV (2002b) Comparison of two methods (visual estimates and filming) for counts of horn flies (Haematobia irritans irritans) (L.) (Diptera: Muscidae). Vet Parasitol 103:227-235.

SAS Institute (1996) Statistical Analysis Systems User's Guide. 4th edition. Cary, $842 \mathrm{pp}$.

Steelman CD, Brown Jr AH, Gbur EE and Tolley G (1991) Interactive Response of the Horn Fly (Diptera:Muscidae) and Selected Breeds of Beef Cattle. J Econ Entomol 84:1275-1282.

Winslow, RB (1992) Reguladores de crescimento de insetos e controle da mosca-dos-chifres. A Hora Veterinária 11:3840 .

Associate Editor: Pedro Franklin Barbosa 